\title{
Cultivating equanimity through mindfulness meditation: A mixed methods enquiry into the development of decentring capabilities in men
}

\author{
Tim Lomas - Trudi Edginton - Tina Cartwright - Damien Ridge
}

\begin{abstract}
Mindfulness meditation is thought to help practitioners become more tolerant of dysphoric emotions by enabling them to cultivate decentring skills. Such skills may be especially useful for male meditators, as men are thought to have particular difficulties regulating their emotions, partly due to masculinity norms related to emotional toughness. However, few studies of mindfulness have focussed specifically on men to explore the intersection between wellbeing and masculinity. Uniquely, we sought to examine the development of decentring capabilities in a non-clinical sample of male meditators using a longitudinal mixed-methods design. Thirty meditators were recruited in London, UK. Participants completed an emotional Stroop task - at two points, a year apart - to assess changes in emotional reactivity linked to meditation. Participants also undertook qualitative interviews at both time points, analysed using a modified constant comparison approach. Together, the two datasets converged to suggest that men did develop decentring skills through meditation, leading to greater equanimity in the presence of negative qualia. In addition to offering insights into the mechanisms underpinning the impact of mindfulness on wellbeing, the study provides a gendered dimension to the analysis of wellbeing strategies like meditation, a dimension which has hitherto been conspicuously absent from recent literature in fields such as positive psychology.
\end{abstract}

Keywords: mindfulness, decentring, cognition, emotional Stroop, wellbeing, masculinity, men

\section{Introduction}

\subsection{Mindfulness and decentring}

Following the development of Kabat-Zinn's (1982) pioneering Mindfulness-Based Stress Reduction (MBSR) programme, academic interest in mindfulness has flourished, with over 500 studies on the subject in 2012 alone (Shonin, Van Gordon, \& Griffiths, 2013). Mindfulness has been harnessed in a diverse range of settings to deliver a multitude of positive outcomes, from alleviating occupational stress in challenging occupations (Shapiro, Astin, Bishop, \& Cordova, 2005) to promoting healthy eating in people with eating disorders (Dalen et al., 2010). So, what is mindfulness? Kabat-Zinn's (2003, p.145) widely-cited 'operational working definition' constructs it as 'the awareness that arises through paying attention on purpose, in the present moment, and nonjudgmentally to the unfolding of experience moment by moment.' This type of awareness appears to represent a core psychological competency that is transferrable across multiple domains, enabling/underpinning a range of cognitive and behavioural strategies that are conducive to wellbeing. As summarised by Grossman, Niemann, Schmidt, and Walach (2004, p.36), the power of mindfulness - and hence of interventions designed to cultivate it - is based 
on a number of factors: (1) people are often unaware of their moment-to-moment experience, and instead operate more on 'autopilot'; (2) mindfulness is a skill that can be cultivated; (3) development is gradual and progressive, requiring practice; (4) better moment-to-moment awareness produces a 'richer and more vivid sense of life'; (5) persistent non-judgmental awareness of mental content leads to less distorted perception and cognition; and (6) accurate perception and cognition can enhance self-efficacy and control over behaviour.

In recent years various theories have been proposed on the mechanisms through which mindfulness exerts its positive effects. Hart, Ivtzan, and Hart (2013) identify two main theoretical schools of thought, one developed by Langer (1989) and colleagues, and the other by Kabat-Zinn (2003) and Shapiro and colleagues (e.g., Shapiro, Carlson, Astin, \& Freedman, 2006). Langer's work has tended to focus on mindfulness as a psychological trait (albeit one that can be cultivated through the practice of meditation), comprising dimensions such as engagement, noveltyseeking, novelty-production, and flexibility. In contrast, theorizing associated with Kabat-Zinn and Shapiro and colleagues operationalizes mindfulness as a cognitive skill that can be trained through practice. The model developed by Shapiro and colleagues has proved particularly influential (with over 1100 citations for Shapiro et al. (2006) as of July 2015, for example). Essentially, Shapiro and colleagues offer a theoretical elucidation of Kabat-Zinn's working definition (cited above), deconstructing this into three key 'axioms' or components: intention (i.e., a teleological motivation for engaging in practice, such as commitment to psychological development); attention (i.e., cognitive processes through which one attends to one's experience); and attitude (i.e., emotional qualities with which one imbues one's attention, like compassion). Together, these three mechanisms combine to generate an overarching 'meta-mechanism' that Shapiro and colleagues refer to as 'reperceiving'; this is described as a 'fundamental shift in perspective,' in which 'rather than being immersed in the personal drama or narrative of our life story, we are able to stand back and witness it' (Shapiro et al., 2006, p.377).

Thus, according to Shapiro et al. (2006), in developing mindfulness, people are above all able to enter into a different relationship with their subjectivity. Practitioners are encouraged to 'stand back' and view subjective qualia as phenomena passing through their internal world, rather than identifying with and attaching to or becoming averse to such qualia (Bishop et al., 2004). This 'standing back' - referred to by Shapiro et al. (2006) as 'reperceiving' - is perhaps more commonly known as 'decentring,' defined as 'the ability to observe one's thoughts and feelings as temporary, objective events in the mind, as opposed to reflections of the self that are necessarily true' (Fresco et al., 2007, p.234). ('Reperceiving,' 'standing back,' and 'decentring' are essentially equivalent, different labels for the same phenomenon, and are often used interchangeably (Hayes-Skelton \& Graham, 2013). For consistency, this paper will use 'decentring' from this point onwards.) Moreover, according to Shapiro et al. (2006), decentring (or 'reperceiving' in their terminology) is in turn theorized to 'lead to' additional mechanisms which in themselves 'contribute to the positive outcomes produced by mindfulness practice' (p.379), including: self-regulation and self-management; emotional, cognitive and behavioural flexibility; values clarification; and exposure.

Thus, according to Shapiro et al. (2006), decentring is the principle mechanism underlying the positive impact of mindfulness-based interventions on mental health. In such interventions, the aim is not to change participants' thoughts/feelings per se, as cognitive therapy might seek to do, but to help people 'become more aware of, and relate differently to' this content (Shapiro et al., 2005, p.165). For example, Mindfulness-Based Cognitive Therapy (MBCT) is an adaptation of MBSR, designed specifically to prevent depressive relapse (Zindel, Segal, Williams, \& Teasdale, 2002). In MBCT, people are taught to decentre from their cognitions, thus helping 
prevent a 'downward spiral' of negative thoughts and worsening negative affect which could otherwise trigger a depressive relapse. Thus MBCT, and mindfulness interventions generally, involve 'retraining awareness' so that people have greater choice in how they relate and respond to their subjective experience, rather than habitually responding in maladaptive ways (Chambers, Gullone, \& Allen, 2009, p.659).

One of the key beneficial outcomes of developing decentring capabilities is the ability to tolerate otherwise distressing qualia. The positive impact of retraining awareness in this way is not limited to depression, but extends to mental health generally. The inability to tolerate distressing qualia is seen as a transdiagnostic factor underlying diverse psychopathologies (Aldao, Nolen-Hoeksema, \& Schweizer, 2010), including depression (Borton, Markowitz, \& Dieterich, 2005) and substance abuse (Garland, Gaylord, Boettiger, \& Howard, 2010). For example, in substance abuse, inability to tolerate distress can lead to people attempting to suppress dysphoria through self-medication, using alcohol and other psychoactive substances to 'blunt' their negative affect (Garland et al., 2010). However, tolerance of dysphoria engendered through mindfulness can lessen the likelihood of people attempting to suppress negative qualia. Regression analyses show trait mindfulness is associated with reduced emotional suppression and increased tolerance of negative stimuli (e.g., Schütze, Rees, Preece, \& Schütze, 2010). Moreover, training in mindfulness can reduce thought suppression, thus helping prevent maladaptive avoidance coping strategies such as self-medication through alcohol (Garland et al., 2010). Similarly, mindfulness interventions for eating disorders can help people become aware of triggers of maladaptive eating habits (e.g., emotional distress), and to stay mindful in the presence of these triggers, rather than reacting by engaging in unhelpful eating behaviours (Dalen et al., 2010).

\subsection{Mechanisms of decentring}

So, one of the key processes underpinning the positive impact of mindfulness on wellbeing is the development of decentring skills. As outlined above, Shapiro et al. (2006) suggest that decentring (or 'reperceiving') comprises three components (intention, attention, and attitude), and leads to at least four mechanisms which impact positively on mental health (self-regulation and selfmanagement; emotional, cognitive and behavioural flexibility; values clarification; and exposure). The question then arises: how does decentring develop? It could be argued that, of the three component mechanisms identified by Shapiro et al. (2006), the training of attention is the most crucial feature of this development. For many researchers, the learned regulation of attention is the defining feature of mindfulness, and meditative practices generally. As Goleman (1988, p.107) puts it, 'the need for the meditator to retrain his attention, whether through concentration or mindfulness, is the single invariant ingredient in every meditation system.' Likewise, Walsh and Shapiro (2006, pp.228-229) define meditation as 'a family of self-regulation practices that focus on training attention and awareness in order to bring mental processes under greater voluntary control.' As this last definition implies, there is a subtle distinction between attention and awareness; although often used synonymously, these are distinct concepts, supervening on different neurophysiological processes (Koch \& Tsuchiya, 2007). Awareness refers to subjective experience, i.e., the 'conscious registration of stimuli, including the five senses, the kinaesthetic senses, and the activities of the mind' (Brown, Ryan, \& Creswell, 2007, p.212). There are different types of awareness: phenomenal awareness is a catch-all term for subjective experience, whereas access awareness describes aspects of conscious experience being available for 'use in reasoning and rationally guiding speech and action' (Block, 1995, p.227). 
In contrast, attention refers to cognitive mechanisms that control which stimuli enter awareness (Rafal \& Posner, 1987). These mechanisms serve to enhance the way information is processed from select areas of the sensory field, moderating cognitive and perceptual processing by directing resources to relevant internal or external stimuli. Thus, while awareness implies sensate 'reactivity,' attention is more like a 'searchlight'; as Austin (1998, p.69) puts it, 'Attention reaches. It is awareness stretched toward something. It has executive, motoric implications. We attend to things.' Attention is theorised as modular, comprising interrelated subcomponents that are controlled by executive processes within a Supervisory Attention System (Norman \& Shallice, 1986). Inhibitory and excitatory cognitive processes work together to direct and switch attentional processes to facilitate different attention modalities. A prominent framework proposes three such modalities, which supervene on functionally distinct but overlapping neural networks: alerting; orienting; and executive attention (Posner \& Petersen, 1990). Alerting (or 'sustained attention') refers to the intensity of concentration, involving on-going readiness for processing stimuli over time. The other networks pertain to attention selectivity. Orienting (or 'selective attention' or 'concentration') regulates and allocates resources to certain stimuli. Executive attention (or 'divided attention' or 'conflict monitoring') involves the monitoring and selection of competing stimuli; this requires 'effortful' top-down processing using various higher order cognitive processes, including inhibition of responses, self-monitoring and planning, and is implicated in the self-regulation and control of behaviour. In addition to these, Mirsky, Anthony, Duncan, Ahearn, and Kellam (1991, p.112) added the faculty of attention switching, namely 'the ability to change focus in an adaptable and flexible manner.'

Researchers have used the above models of awareness and attention to conceptualise the cognitive mechanisms of mindfulness, and meditation more broadly. A distinction is frequently made between two types of meditation practice (Lutz, Slagter, Dunne, \& Davidson, 2008): focussed attention (FA), which refers to concentrative, sustained attention on an object; and openmonitoring $(\mathrm{OM})$, which involves the receptive monitoring of the broader moment-to-moment content of experience. Lutz et al. (2008) argue that FA-type practices involve the development of all four attention networks: sustained (towards a target like the breath), monitoring (to prevent the mind 'wandering'), switching (disengaging from distractions), and selective (redirecting attention back to the meditative object). In contrast, OM does not involve focusing attention on particular stimuli, but is, rather, a broad receptive awareness, i.e., 'an open field capacity to detect arising sensory, feeling and thought events within an unrestricted 'background' of awareness, without a grasping of these events in an explicitly selected foreground or focus' (Raffone \& Srinivasan, 2010, p.2). In OM, passing qualia are registered as they arise, but not 'held on to' (Grossman et al., 2004, p.36). Given these descriptions, mindfulness can be characterised as a state of OM. That said, mindfulness practices invariably begin not with OM, but with FA-type exercises, such as a focus on the breath. Thus, within a practice, FA is generally needed as a precursor to OM, since one's attention must first be stabilised through concentration in order to prevent the mind 'wandering' during OM (Chiesa, Calati, \& Serretti, 2011).

The notion that meditation develops these attention and awareness capacities has been corroborated empirically. Experienced meditators generally score higher than novices on most attention measures, including selective (Hodgins \& Adair, 2010), sustained (Jha, Krompinger, \& Baime, 2007) and executive attention (Moore \& Malinowski, 2009). Moreover, longitudinal studies of novices learning meditation have found increases in most attention capacities related to meditation practice, including selective (Jha et al., 2007), executive (Wenk-Sormaz, 2005), sustained (Zeidan, Johnson, Diamond, David, \& Goolkasian, 2010) and switching attention (Heeren, Van Broeck, \& Philippot, 2009). Early stages of training in a meditation 'career,' 
involving a primary focus on the development of FA, are associated more frequently with improvements in selective and executive attention, while later phases more frequently pertain to enhancements in OM, i.e., in unfocused sustained attention (Chiesa et al., 2011). Together, the training of these different attention modalities means that mindfulness is viewed as a metacognitive skill that enables 'the self-regulation of attention' (Bishop et al., 2004, p.233). Conceivably, it is this development of self-regulatory attention capacities that contributes to the emergence of decentring skills in meditation. However, this hypothesis has not been directly tested, as the present study seeks to do.

\subsection{Examining decentring}

One way of exploring this hypothesis - i.e., that the cultivation of attention skills through meditation enables practitioners to develop decentring capabilities - is through a variant of the classic Stroop (1935) paradigm, a cognitive task which assesses executive attention. The original Stroop task requires participants to name the ink colour of a colour word, where slower reaction times (RTs) are observed in 'incongruent' conditions (e.g. "blue" written in red ink) than in congruent conditions ("blue" written in blue ink). One explanation attributes the different RTs between congruent and incongruent Stroop conditions to 'interference' arising from conflict between different processing pathways underlying colour-naming and word-reading, caused by 'the simultaneous activation of incompatible and competing representations' (Botvinick, Cohen, \& Carter, 2004, p.541). Longitudinal studies indicate that meditation can enhance Stroop performance, which is interpreted as evidence that meditation can facilitate the development of executive attention (Kozasa, Radvany, Barreiros, Leite, \& Amaro, 2008). The particular variation of the paradigm that potentially links attention development to decentring capabilities is the emotional Stroop, in which participants are required to name the ink colour of words which differ in terms of emotional salience (Williams, Mathews, \& MacLeod, 1996). In general, reaction time for emotional words is slower than reaction time for neutral words, especially for words that are particularly meaningful to a person (Riemann \& McNally, 1995). The emotional Stroop is used in clinical assessment as an adjunctive diagnostic tool to indicate psychopathology, as patients are often slower to name the colour of a word associated with their condition (Williams et al., 1996). Theorists explain such findings in terms of cognitive biases, where certain stimuli have greater emotional salience for some people, who then direct their attention to the emotional meaning of the words, rather than to the task in hand (Mathews \& MacLeod, 1994).

Theoretically, it is conceivable that mindfulness training should enhance emotional Stroop performance. Rather than getting drawn into semantic processing of emotional stimuli (thus hindering RT), the enhanced attention skills of practitioners - involving a combination of attentional control, inhibition and flexibility - should enable them to redirect their concentration onto the task at hand (Bishop et al., 2004). One might hypothesise that it is this type of skilful redeployment of attention that underlies the development of decentring capabilities, and enables practitioners to cultivate the ability to tolerate negative stimuli (i.e., being aware of such stimuli, but without engaging in destructive elaborative processing of them). (One must add that attention redeployment is not the only plausible mechanism underlying decentring. As noted above, Shapiro et al. (2006) also include intention and attitude as important components. Buddhist psychological theory also emphasizes the role of insight/wisdom in decentring, e.g., understanding the transient and 'illusory' nature of stimuli (Goleman, 1988).) However, so far, this hypothesis has not been borne out in the few studies to examine the impact of meditation practice on the cognitive processing of emotional stimuli. A study of 33 long-term meditators failed to find any connection between mindfulness ability and emotional Stroop performance 
(Lykins, Baer, \& Gottlob, 2012). Chambers, Lo, and Allen (2008) compared novice meditators with matched controls on a version of the Internal Switching Task (a measure of sustained and switching attention) that involved a neutral and an affective condition. Strikingly, while both groups exhibited slower RTs in the affective condition, this difference was more pronounced among the meditators, suggesting that they were more reactive to the emotional stimuli. Thus, although it could be hypothesised that mindfulness training should enable enhanced performance on the emotional Stroop task - i.e., avoiding elaborative processing of emotional stimuli - so far this has not been shown in practice. The present study aims to revisit this hypothesis.

\subsection{Men and masculinity}

A further innovative element in the present paper is the focus on a population that has hitherto not been studied specifically in relation to mindful decentring, or the emotional Stroop generally: a non-clinical sample of male meditators. Most studies using the emotional Stroop paradigm examine clinical populations (e.g., using it to help identify psychopathologies); thus studying task performance in a general population is unusual. The originality of this focus is augmented by the decision to study men specifically. The rationale for this decision is that men are seen as particularly liable to experience problems with emotional regulation. Gender theorists argue that masculinity norms concerning emotional toughness can lead to men dissociating or disconnecting from their emotions (Addis, 2008). Levant (1998) even proposed the notion of 'normative male alexithymia' to describe how gendered socialization pressures can mean males are discouraged from, and even punished for, expressing emotions; the consequence is a tendency among men towards an 'affective style' referred to as 'restrictive emotionality.'

This affective style is in turn linked to mental health issues in men. For instance, although women are commonly viewed as being more susceptible to psychopathologies such as depression (McManus, Meltzer, Brugha, Bebbington, \& Jenkins, 2009), there is a concern that men's liability towards restrictive emotionality means their distress may be expressed in indirect ways. Whereas women are viewed as more likely to 'internalize' their distress - thus meeting conventional generic diagnostic criteria for depression - men are considered more likely to seek to suppress or avoid their distress through 'externalising' responses such as risk-taking, substance use, and anger (Pollack, 1998). Such responses are seen as at least partly responsible for statistical trends such as the rate of suicide among men in the UK being three-and-a-half times higher than the rate among women (Office for National Statistics, 2014), and men accounting for two-thirds of all deaths relating to alcohol use (Office for National Statistics, 2012). As such, a particularly salient question is whether mindfulness meditation can help men specifically to decentre from negative qualia, thus enabling them to better tolerate feelings of distress, rather than seeking to blunt, avoid, or suppress these feelings through the maladaptive responses highlighted above. Thus, the research question that the current study seeks to answer is this: Can the practice of mindfulness help men to decentre from negative qualia (as indexed by improved longitudinal performance on an emotional Stroop task, and corroborated by qualitative interviews)?

\section{Methods}

\subsection{Overview and Design}

A longitudinal mixed methods design was used. Thirty male meditators were recruited using a maximum variation sampling strategy. Semi-structured narrative interviews were conducted with participants on their entry to the study (T1), and again a year later (T2). Twenty-nine of 
these participants also completed a cognitive testing session at both time points, on the same day as the interview (participants first completed the test session, and then, after an interval of 10 minutes, undertook the interview).

\subsection{Participants}

Inclusion criteria were that participants be over 18 and currently practicing meditation (though not as part of a clinical intervention). A purposive maximum variation sampling design was used, in which people with a wide range of demographic backgrounds and meditation experiences were sought (Marshall, 1996). Recruitment ended once saturation was reached (additional interviews were not deemed to be generating any substantive new themes). A diverse group of participants was recruited, all of whom lived and/or worked in London. Recruitment was principally through meditation centres in London, UK, that were affiliated to the Friends of the Western Buddhist Order (FWBO, recently renamed the Triratna Buddhist Community), one of the largest Buddhist movements in the UK (Bluck, 2006), The FWBO is unorthodox in that it does not identify with one particular Buddhist tradition, but rather has syncretically selected practical/doctrinal elements from various traditions, from Therevadan vipassanā meditation practices to Tibetan deity rituals. Twenty-six participants were affiliated to the FWBO: 10 were very closely involved with an FWBO centre (i.e., lived and/or worked there); 11 regularly attended one; and 5 had only occasional involvement. Two further participants were affiliated to other traditions, and two final participants were unaffiliated to any group.

The FWBO teaches two core practices: mindfulness (various forms, but most commonly the mindfulness of breathing), and the metta bhavana (operationalized in the literature as lovingkindness meditation (LKM)). Thus, the 26 participants affiliated to the FWBO all practiced both mindfulness (mainly the mindfulness of breathing) and LKM to some extent, both generally and during the research year, as did three of the participants unaffiliated to the FWBO. Additionally, some participants engaged in other practices, such as 'Sādhanā' (an 'advanced' deity visualization meditation). Levels of mindfulness practice (and other forms of meditation) over the course of the year varied greatly among participants, ranging from one session of mindfulness per week (with occasional periods during which practice ceased), up to two mindfulness sessions per day for the most committed practitioner. As a final point, although this variation in the types and amounts of meditation practice among participants may be considered 'messy' from a methodological perspective, it is arguably reflective of the realities of meditation practice away from controlled clinical settings, since practice habits not only vary from person to person, but also change and fluctuate over time for individuals themselves.

\subsection{Experimental session}

Twenty-nine participants took part in an experimental session - repeated twice, about a year apart - in which they were assessed on: an emotional Stroop task; a measure of verbal fluency; and the National Adult Reading Test (Nelson \& Willison, 1991) as an index of intellectual functioning (IQ) to contextualise task performance. The emotional Stroop paradigm was based on Becker, Rinck, Margraf, and Roth (2001). There were three conditions: positive words (e.g. "friendly"), negative anxiety-related words (e.g. "death") and neutral words (e.g. "pencil"). Each condition featured 12 different words, repeated six times, generating a list of 72 words, arranged on one card in six columns. Each word was printed in black, brown, green, red, blue or orange ink. In the testing session, participants were required to state aloud the ink colour of the words as fast as possible. At both T1 and T2, all participants completed all three conditions, in the same 
order: neutral, negative, positive. Participants were timed on how long they took to complete each card.

Verbal fluency (ability to access and retrieve words within specific constraints) is considered to reflect executive function and attentional switching and flexibility. It is differentiated into phonemic (retrieving words on the basis of phonemic lexical properties) and semantic fluency (retrieving knowledge from within a semantic framework). Phonemic fluency was assessed using the FAS task (also referred to as the Controlled Oral Word Association Test; Benton, 1989), and semantic fluency using a category task. The FAS task required participants to produce words (excluding proper nouns) beginning with specific letters of the alphabet. The letters were $\mathrm{F}, \mathrm{A}$ and $\mathrm{S}$ at T1, and P, A and S at T2. At both T1 and T2 participants underwent three consecutive trials, one for each letter, with each trial lasting 60 seconds. For semantic fluency, the category task required participants to generate as many category exemplars as possible, in 60 seconds, for a specific given category (animals at T1, and food/drink at T2).

\subsection{Qualitative data collection and analysis}

Participants were all interviewed at T1 for up to two hours, with a short follow-up interview at T2 lasting up to one hour. At T1, the first half of the interview involved eliciting narratives leading up to, and following on from, participants' engagement with meditation. The interview began with a set request: "Tell me a bit about life before meditation," followed by probes to elicit relevant narratives. The second part focused on specific areas of interest, such as wellbeing, stress and coping. T2 interviews were unstructured, apart from a set opening request: "Tell me a bit about how this year has been." The data were analysed using a 'modified' constant comparison approach (Strauss \& Corbin, 1998); this follows the protocol of modified grounded theory, but omits the final stage of developing a theoretical framework, instead focusing on open and axial coding, aiming to articulate inter-relations between key themes. The first phase of coding involved close reading of the first six T1 transcripts, line by line, to identify emergent themes, which generated 80 codes. Subsequent transcripts were examined paragraph by paragraph for additional codes, with a final figure of 105 . This paper concentrates on data pertaining to participants' experiences of learning to decentre through mindfulness meditation. Twelve codes were identified relating directly to decentring. The next stage involved the generation of a tentative conceptual framework: codes were compared with each other, and grouped into three overarching categories according to conceptual similarity. These three categories constitute the three overarching 'themes' outlined in the qualitative results section.

\section{Results}

\subsection{Participant descriptive statistics}

Descriptive statistics for the participants in terms of age, $I Q$, and general meditation experience (i.e., numbers of years meditating, and hours per week meditating), are shown in table 1 below.

Table 1. Participant descriptive statistics

\begin{tabular}{lccc}
\hline Demographic & Range & Mean & Std. dev. \\
\hline Age & $27-61$ & 42.5 & 9.1 \\
IQ & $97-121$ & 114.5 & 6.5 \\
Years meditating & $1-26$ & 10.8 & 7.1 \\
Hours/week meditating & $1-8$ & 4.1 & 1.8 \\
\hline
\end{tabular}


As elucidated above, mindfulness meditation (mainly the mindfulness of breathing) was the dominant practice, both within the group ( 29 out of 30 participants practiced this with some level of regularity) and for individuals themselves (it was practiced more commonly than any other type of meditation). More specific details on the precise amount of time devoted to specific practices were not obtained.

\subsection{Quantitative results}

In the emotional Stroop, the dependent variable (DV) was the time in seconds taken to complete the list of 72 words for each condition (i.e., state aloud the ink colour of every word). Thus, each participant had six DV scores: completion time for each of the three conditions (neutral, negative, and positive) at two time points (T1 and T2). At T1, participants were slowest on negative words, and fastest on positive words, while at T2, participants were slowest on neutral words, and quickest on negative words, as shown in table 2 below.

In terms of analysing the development of decentring capabilities, the key outcome was longitudinal change in the differential between performance on neutral words and performance on negative words. The differential was calculated by subtracting the neutral words' completion time from the negative words' completion time, producing a 'relative negative score' (reflecting the relative impact of negative words on task performance). Here, a positive score means a slower performance on negative words than neutral words; thus the higher the score, the greater the emotional reactivity. Conversely, a negative score means quicker performance on negative words than neutral words; thus the closer the scores are to zero (or fall below zero), the less the reactivity. Participants were slower on negative words than neutral words at T1 (producing a positive differential score), but quicker on negative words than neutral words at T2 (producing a negative differential score), as shown in table 2 and figure 1 below.

Table 2. Stroop mean times and differentials in seconds (standard deviation in parentheses)

\begin{tabular}{llllcr}
\hline & Neutral & Negative & Positive & $\begin{array}{l}\text { Neg.-neut. } \\
\text { Differential }\end{array}$ & $\begin{array}{l}\text { Pos.-neut. } \\
\text { Differential }\end{array}$ \\
\hline $\mathrm{T} 1$ & $60.38(10.11)$ & $62.17(10.67)$ & $61.62(8.22)$ & $1.79(4.55)^{*}$ & $1.24(6.02)$ \\
$\mathrm{T} 2$ & $64.41(14.73)$ & $63.03(10.91)$ & $64.24(12.06)$ & $-1.38(7.92)^{*}$ & $-0.17(8.26)$ \\
\hline${ }^{*} \mathrm{p}=.029$, one-tailed & & & &
\end{tabular}

To analyse the change in differential over time, a paired-sampled T-test was conducted. This revealed that there was a significant longitudinal change in the 'relative negative score', $t(29)=$ $1.97, p=.029$, one-tailed, $d=0.73,95 \% \mathrm{CI}[-.13,6.47]$, changing from a positive differential at $\mathrm{T} 1(\mathrm{M}$ $=1.79, S D=4.55)$ to a negative differential at $\mathrm{T} 2(M=-1.38, S D=7.92)$. 
Figure 1: Line graph showing the change in the 'negative-neutral' and the 'positive-neutral' Stroop differentials from $\mathrm{T} 1$ to $\mathrm{T} 2$

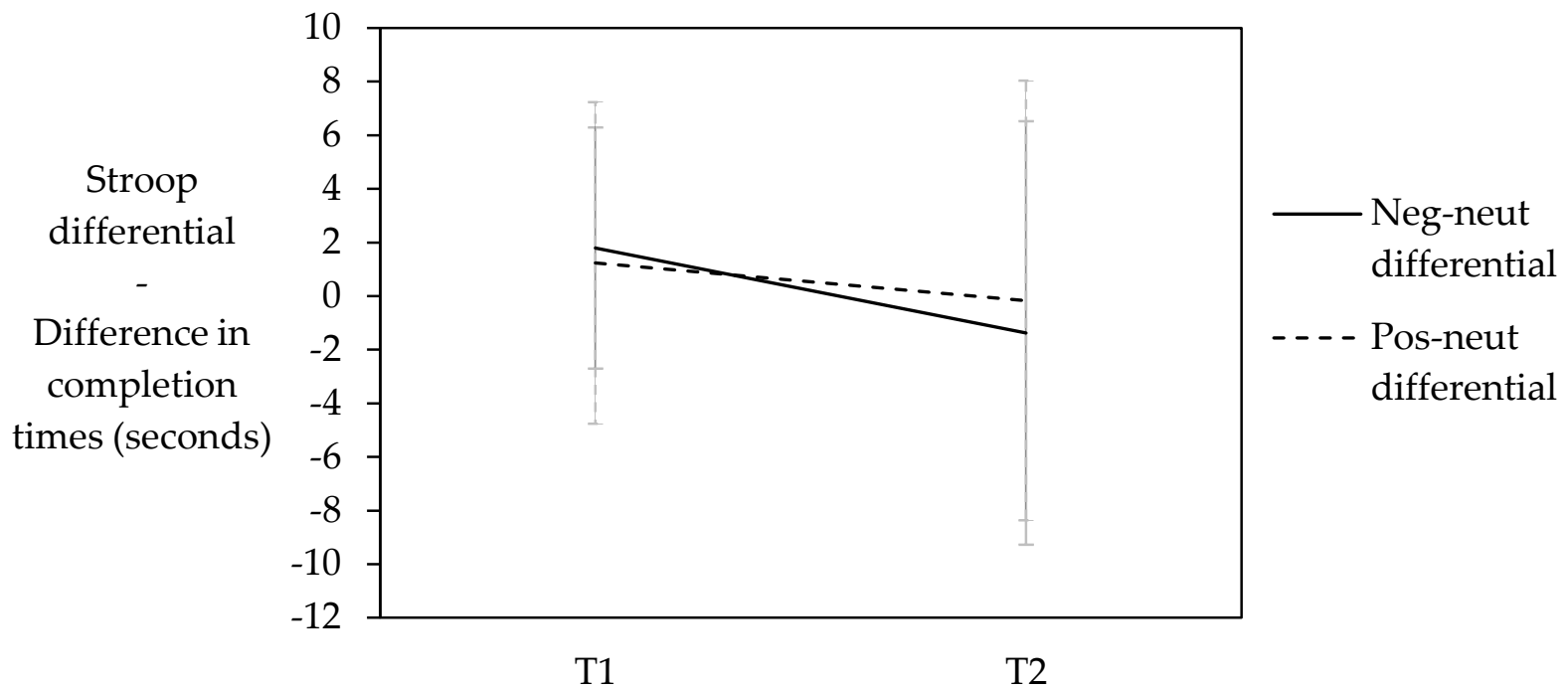

A second key outcome was longitudinal change in the differential between performance on positive words and performance on neutral words. The differential was calculated by subtracting the neutral words' completion time from the positive words' completion time, producing a 'relative positive score.' A positive score means a slower performance on positive words than neutral words. A negative score means a quicker performance on positive words than neutral words. Participants 'improved' their differential from T1 to T2, i.e., becoming quicker on positive words relative to neutral words, as shown in table 3 and figure 2 below.

Table 3. Verbal fluency - phonemic and semantic fluency mean scores (standard deviation in parentheses).

\begin{tabular}{llc}
\hline & \multicolumn{1}{c}{ T1 } & T2 \\
\hline Phonemic (FAS) & $47.34(9.99)^{*}$ & $55.86(12.76)^{*}$ \\
Semantic (categories) & $73.59(11.81)^{* *}$ & $84.28(16.60)^{* *}$ \\
\hline
\end{tabular}

${ }^{*} \mathrm{p}=.001$

** $\mathrm{p}<.001$

To analyse the change in differential over time, a paired-sampled T-test was conducted. This revealed that there was no significant longitudinal change in the 'relative positive score,' $t(29)=$ $0.89, p=.38, d=0.33,95 \%$ CI $[-1.83,4.66]$, although the differential did reduce from T1 $(M=1.24$, $S D=6.02)$ to $\mathrm{T} 2(M=-0.17, S D=8.26)$

In the verbal fluency tasks, the DV was the number of different words produced in 60 seconds for each trial. A phonemic fluency score was obtained by calculating the mean score across these three trials (F, A and S at T1; P, A, and S at T2). The semantic fluency score was simply the DV from the category trial. Participants improved their phonemic and semantic fluency scores from $\mathrm{T} 1$ to $\mathrm{T} 2$, as shown in the table and figure below.

To analyse the change in differential over time, a paired-sampled T-test was conducted. There was a significant longitudinal change in phonemic fluency, $t(29)=-3.76, p=.001, d=1.39$, $95 \%$ CI $[-13.16,-3.87]$, with lower scores at T1 $(M=47.34, S D=9.99)$ than T2 $(M=55.86, S D=$ 12.76). There was also a significant longitudinal change in semantic fluency, $t(29)=-2.36, p=0.25$, 
$d=0.88,95 \% \mathrm{CI}[-4.06,-.287]$, with lower scores at T1 $(M=26.24, S D=4.8)$ than $\mathrm{T} 2(M=28.41, S D$ $=6.13$.

Figure 2: Line graph showing the change in phonemic and semantic fluency from T1 to T2.

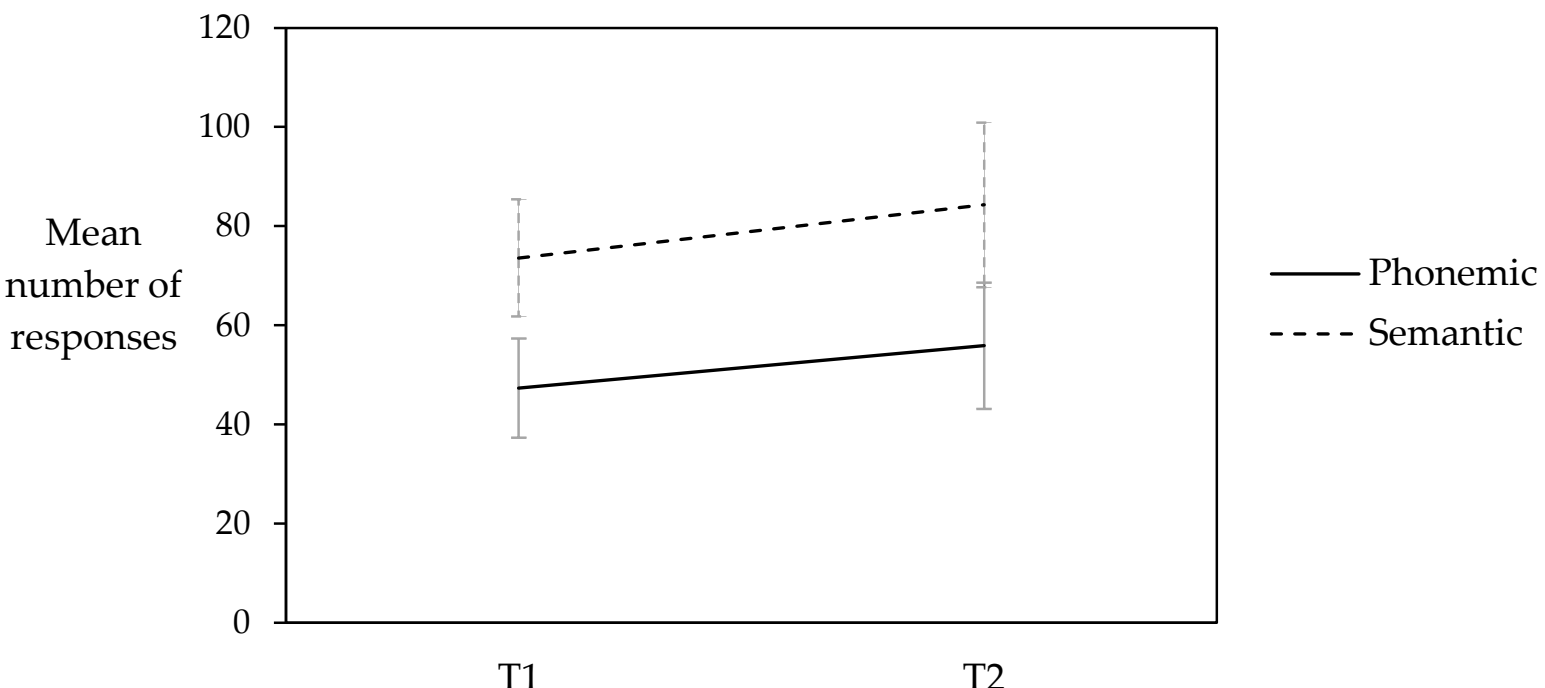

\subsection{Qualitative results}

One overarching theme emerged from our analysis: through practicing mindfulness meditation, men reported developing decentring capabilities. Under this broad theme, there were three interlinked themes, each with subthemes, as shown in table 4 below. The number of participants endorsing each theme and sub-theme is indicated in the table in parentheses; although such quantification is more commonly the province of content analysis, arguments have recently been made for extending such practices to qualitative methods more generally in order to improve the presentation of qualitative results (e.g., Anderson, 2010), as has been attempted here.

The themes and sub-themes express a general pattern of development of decentring skills, and are connected as follows (with numerical labels for subthemes, detailed in table 4 below, in parentheses). For most men, meditation was the first time they had introspected in any systematic way (1.1.), and many were surprised by aspects of their phenomenological experience (1.2.). Nevertheless, participants also appreciated that mindfulness (and other forms of meditation) could have a positive impact on wellbeing (1.3.), such as helping them become more aware of their feelings (1.4.). Men described learning to deploy their attention skilfully, beginning to decentre from their subjective qualia (2.1.), which was reported as a feeling of 'stepping back' (2.2.). Doing so helped participants to appraise their emotions with greater clarity (2.3.), while also becoming less identified with these emotions (2.4.). These decentring skills consequently had a positive impact on wellbeing. Participants were better able to tolerate distressing thoughts/feelings, which previously they might have tried to suppress or avoid (3.1.). This tolerance often, though not always, generated a sense of calmness (3.2.). More generally, being less immersed and invested in the vagaries of their emotional world meant that men were less reactive and experienced a greater sense of self-control (3.3.), and opened up to new and different feelings of wellbeing (3.4.). 
Table 4. Qualitative themes

\begin{tabular}{|c|c|c|}
\hline Theme & Sub-theme & Example quote \\
\hline \multirow{5}{*}{$\begin{array}{l}\text { 1. }(\mathrm{n}=27) \\
\text { Emotional } \\
\text { engagement } \\
\text { through } \\
\text { meditation }\end{array}$} & 1.1. $(n=16)$ & "[I took] a mindfulness based cognitive therapy course, [which] was \\
\hline & $\begin{array}{l}\text { Turning inwards in } \\
\text { meditation (12) }\end{array}$ & the introduction to watching my mind in a way." (P26) \\
\hline & $\begin{array}{l}\text { 1.2. }(\mathrm{n}=19) \\
\text { Initial unfamiliarity } \\
\text { with mind }\end{array}$ & $\begin{array}{l}\text { "There's the shock [of] really encountering your mind for the first } \\
\text { time!" (P20) }\end{array}$ \\
\hline & $\begin{array}{l}\text { 1.3. }(\mathrm{n}=12) \\
\text { Sensing the positive } \\
\text { potential }\end{array}$ & $\begin{array}{l}\text { "It was a bit weird, and I really [didn't] understand what I was } \\
\text { doing counting my breaths, but it [felt] like I [did] a useful thing } \\
\text { that might [help my] depression." (P28) }\end{array}$ \\
\hline & $\begin{array}{l}\text { 1.4. }(\mathrm{n}=20) \\
\text { Awareness of } \\
\text { emotions/thoughts }\end{array}$ & $\begin{array}{l}\text { "I can tell if something's not right, maybe I have anxiety... then it } \\
\text { dawns on me, 'Oh I'm upset aren't I,' and it's like, 'Oh ok, just } \\
\text { allow those feelings to come through.'" (P30) }\end{array}$ \\
\hline \multirow[t]{4}{*}{$\begin{array}{l}\text { 2. }(\mathrm{n}=18) \\
\text { Learning to } \\
\text { decentre }\end{array}$} & $\begin{array}{l}\text { 2.1. }(\mathrm{n}=7) \\
\text { Being interested but } \\
\text { not involved }\end{array}$ & $\begin{array}{l}\text { "It's finding this line between not pushing it away... but not getting } \\
\text { caught up in it and feeding it... A particular type of attention... } \\
\text { interested, but not getting caught up in it (P5) }\end{array}$ \\
\hline & $\begin{array}{l}\text { 2.2. }(\mathrm{n}=11) \\
\text { Stepping back }\end{array}$ & $\begin{array}{l}\text { "I'm able to step back more easily and become aware of what's going } \\
\text { on, rather than just being in the flow of what's going on." (P10) }\end{array}$ \\
\hline & $\begin{array}{l}\text { 2.3. }(\mathrm{n}=8) \\
\text { Greater clarity through } \\
\text { distance }\end{array}$ & $\begin{array}{l}\text { "I see my own kind of states a bit clearer now, I'm not likely just to } \\
\text { get buried and get lost in them." (P24) }\end{array}$ \\
\hline & $\begin{array}{l}\text { 2.4. }(\mathrm{n}=8) \\
\text { Dis-identifying with } \\
\text { mental content }\end{array}$ & $\begin{array}{l}\text { "I realised there was this very, very critical voice [in my head] ... } \\
\text { [Then I thought], 'What if that... version of reality that it's telling } \\
\text { me is not actually fair [or] true.' (P9) }\end{array}$ \\
\hline \multirow{4}{*}{$\begin{array}{l}\text { 3. }(\mathrm{n}=22) \\
\text { Enhanced } \\
\text { wellbeing } \\
\text { through } \\
\text { decentring }\end{array}$} & $\begin{array}{l}\text { 3.1. }(\mathrm{n}=16) \\
\text { Tolerance of negative } \\
\text { qualia }\end{array}$ & $\begin{array}{l}\text { "It feels like building up a sort of stronger vessel to hold those } \\
\text { uncomfortable feelings... I'm able to contain that... I don't have to } \\
\text { try to get away from the experience." (P26) }\end{array}$ \\
\hline & $\begin{array}{l}\text { 3.2. }(\mathrm{n}=10) \\
\text { Consequent calmness } \\
\text { and lack of distress }\end{array}$ & $\begin{array}{l}\text { "In seeing the best and worst of ourselves, we are also bigger to hold } \\
\text { it... The calmness is also like a bigness. One can hold the highs and } \\
\text { lows of oneself." (P29) }\end{array}$ \\
\hline & $\begin{array}{l}\text { 3.3. }(\mathrm{n}=8) \\
\text { Self-efficacy and } \\
\text { control }\end{array}$ & $\begin{array}{l}\text { "It's like you've got a third eye that's watching yourself; it's saying, } \\
\text { 'no don't do that, that's not nice' ... watching your own behaviour } \\
\text { and allowing you to enjoy life." (P11) }\end{array}$ \\
\hline & $\begin{array}{l}\text { 3.4. }(\mathrm{n}=24) \\
\text { Feelings of wellbeing }\end{array}$ & $\begin{array}{l}\text { "There was that sense of space, of choice opening up, of } \\
\text { experiencing being a little more vivid, more bright; just my } \\
\text { experience being a little more easy to be with." (P29) }\end{array}$ \\
\hline
\end{tabular}

\section{Discussion}

The results indicate that practicing mindfulness can lead to enhanced decentring skills, and that these skills can enable people to better tolerate feelings of discomfort and distress. Moreover, the current study is unique in exploring this development in men specifically. Men are regarded as having particular issues in respect of emotional suppression (Addis, 2008): masculinity norms related to toughness are seen as contributory factors in the development of a maladaptive affective style, known as restrictive emotionality, that is common in men (Levant, 1998). Development of such a maladaptive affective style can result in men struggling to tolerate or manage negative emotions, and instead seeking to blunt or avoid these emotions through various deleterious 'externalising' behaviours such as substance use, aggression or suicide (Pollack, 
1998). Such is the prevalence of restrictive emotionality in men that Levant (1998) refers to this as 'normative male alexithymia.' However, results here suggest that this affective style is not inevitable. Through practices such as mindfulness meditation, men can learn to re-connect with their emotions, and develop a more adaptive affective style. Moreover, the positive impact of meditation is not limited to re-connecting emotionally. Mindfulness appears to facilitate a stance of decentring, via the development of capacities such as executive attention, which means practitioners not only develop better awareness of their emotions, but also and crucially, greater tolerance of them. Thus, men here were able to feel relatively comfortable in the presence of these difficult qualia, rather than seeking to avoid or blunt them, as they said they previously often sought to do. The current study is also innovative in employing a mixed methods design to explore this development of decentring; thus, we have evidence for this development from both quantitative and qualitative datasets.

Firstly, longitudinal quantitative results from the emotional Stroop task provide indirect evidence that men developed decentring skills through practicing mindfulness meditation. The key outcome in this task was the differential between negative and neutral performance. This differential can be interpreted as an index of emotional reactivity, gauging the extent to which attention processing is affected by the negative content of stimuli. Here, this differential decreased from $\mathrm{T} 1$ to $\mathrm{T} 2$. The inference is that participants were less emotionally affected by negative stimuli at the second testing session. This interpretation is based on the fact that the emotional Stroop is used in clinical assessment to help identify psychopathology (Williams et al., 1996): people with a particular disorder perform more slowly on tasks featuring words relating to that condition, since such words are more personally salient; thus, people get drawn into semantic processing of the stimuli, rather than focusing on the set task. On this reading, improved performance on a Stroop task might be taken as indicative of reduced psychopathology in a clinical patient. Transposed to a non-clinical sample, as in the present study, reduced emotional reactivity to negative stimuli might be interpreted as reflecting increased tolerance of such stimuli. Taking the Stroop data alone, such an interpretation is rather speculative; however, in conjunction with the other data, this interpretation is more tenable. Firstly, there were significant improvements over time in executive attention, as indexed by the verbal fluency tasks; these findings suggest that participants were developing skills related to attentional control, inhibition and flexibility, thus developing the cognitive mechanisms that could facilitate greater tolerance of negative qualia. Secondly, the qualitative data also corroborated this notion of participants cultivating greater tolerance (as elaborated upon below). Moreover, this development is what might reasonably be expected on theoretical and empirical grounds in light of previous work associating mindfulness with enhanced affective tolerance (Bishop et al., 2004).

Furthermore, it is possible that this increased tolerance was linked to the cultivation of decentring skills through practicing mindfulness. Of course, in terms of the quantitative data alone, this possibility cannot be substantiated due to the primary limitation of the study: the absence of a control group. (The reason for this omission is that, unlike most mixed methods research, the research was 'qualitatively driven' (Mason, 2006), and therefore did not prioritize a conventional experimental design. That is, the primary focus of the research was qualitative interviews, with quantitative data gathered as an adjunct to this for the purposes of 'interrogating' or elucidating the qualitative data.) Thus, although participants did become less reactive to negative stimuli over time, this cannot be definitively attributed to the practice of mindfulness itself. However, again, this possibility is strengthened by the qualitative data, which 
was particularly useful in shedding light on participants' subjective experiences of learning to decentre.

The qualitative analysis corroborated Shapiro et al.'s (2006) theoretical model of mindfulness, showing how the various components of their model operated in the context of participants' actual meditation practice. As elucidated above, Shapiro et al. (2006) argue that decentring (or 'reperceiving') comprises three components: intention, attention, and attitude. The quantitative data provided evidence suggestive of the development of attention, as discussed above. This evidence was corroborated by the qualitative data, as participants specifically described the development of attention skills, e.g., learning to 'watch' their mind (e.g., quote 1.1.). However, the qualitative data also pointed to the importance of the other two components identified by Shapiro et al. (2006). Firstly, intention played a crucial role (which is often overlooked in the meditation literature) as the fundamental pre-requisite for subsequent attention development. A significant aspect of participants' narratives was the long road they had travelled in life before developing the requisite intention to engage with their mental health through meditation, which corroborates Levant's (1998) point above about the prevalence and durability of restrictive emotionality in men. It was often not until a crisis occurred (e.g., a breakdown) that men finally developed the motivation and courage to 'do something,' i.e., try meditation. The urge to improve their mental health thereafter constituted a strong element of their intention (as per quote 1.3). Learning to imbue attention with a particular attitude was likewise crucial, as encapsulated by quote 2.1; this shows that intention and attention are themselves insufficient for decentring - one must still develop the difficult skill of attending in a compassionate and 'nonjudgmental' way, as Kabat-Zinn (2003) and others have emphasized.

The qualitative data further corroborate Shapiro et al.'s (2006) contention that learning to decentre (or 'reperceive') in turn leads to additional mechanisms that have a beneficial impact upon wellbeing. For instance, self-regulation/self-management and emotional, cognitive and behavioural flexibility are both reflected in quotes 3.3 and 3.4, which confirm Chamber's et al.'s (2009, p.659) contention that decentring facilitates 'greater choice' in how one responds to subjective experience. Likewise, exposure - defined by Shapiro et al. (2006) as the ability to experience 'even very strong emotions with greater objectivity and less reactivity' (p.381) - is evident in quotes 3.1 and 3.2. This corroborates clinical work which has found that mindfulness training can help people stay 'present' in the face of uncomfortable emotional triggers, rather than reacting though maladaptive behaviour patterns such as alcohol use (Garland et al., 2010) or dysfunctional eating behaviours (Dalen et al., 2010).

Interestingly, participants were also less affected by positive stimuli at T2 than T1 (although this change was not significant). Taken together with the reduced reactivity to negative stimuli, this perhaps suggests that men cultivated increased equanimity to emotional stimuli in general. That is, participants became less reactive over time to both negative and positive stimuli (as indexed by improved performance on the respective conditions of the Stroop task), although this reduction was more pronounced (i.e., statistically significant) with respect to negative stimuli. This equanimity reinforces a key theoretical assumption regarding the impact of mindfulness on mental health outcomes: that it helps practitioners to decentre from phenomenological content generally (i.e., irrespective of valence), and thus refrain from responding to negative emotional stimuli in maladaptive ways, such as suppression or avoidance. Moreover, such decentring may be particularly helpful for men specifically: since these kinds of maladaptive patterns of emotional responding are linked to mental health issues in men (Addis, 2008), the findings suggest that mindfulness meditation may be an effective strategy that can help men adopt more helpful patterns of emotional engagement. 
Limitations of the study mean that these interpretations are somewhat speculative, and need further testing and validation. In particular, as noted above, the lack of a control group means the longitudinal improvements in the Stroop performance cannot be definitively ascribed to meditation (although the qualitative evidence suggests that this is a reasonable conjecture). There are other issues with quantitative testing; however, these are arguably not a concern in the present study. For instance, longitudinal paradigms featuring repetitions of a particular task are liable to practice effects, in which practice and experience gained on initial engagement with the task might enhance subsequent performance. However, while this is a legitimate concern for short test-retest intervals, a test-retest interview of a year is generally deemed adequate to ensure that such effects are minimal (Hausknecht, Halpert, Di Paolo, \& Moriarty Gerrard, 2007). Nevertheless, with the Stroop task, one might still argue that practice effects were operative within each session, since participants completed three trials in each session - undertaking the neutral, negative and positive conditions (in that order). It has been found that Stroop performance can be improved with short-term practice, as people find ways to minimise interference between the competing task demands of colour recognition and semantic encoding, potentially leading to a diluted Stroop effect for later conditions (MacLeod \& Dunbar, 1988). Such dilution is not a concern here, however. The order in which the conditions were presented may have affected absolute performance times (i.e. neutral words were presented before negative words, thus participants may have found negative words easier due to practice effects). However, the key outcome was not absolute performance times, but relative performance times, i.e., the negative-neutral differential at $\mathrm{T} 1$ and $\mathrm{T} 2$. As the order of the conditions was kept constant at T1 and T2, this meant both sessions were subject to the same practice effects (e.g. negative words being easier at T1 and T2). As such, analysis of the change in differential from T1 to T2 was unaffected.

That said, it is possible that even if practice effects were not operant per se, participants undertook the T2 session in a different mood or 'spirit' than the T1 session, having already been exposed to the experience. Assessing participants' mood is difficult (without having specifically sought to do so), and so any interpretations offered here are necessarily speculative. Nevertheless, it is conceivable that participants felt more relaxed and less anxious at the T2 encounter, benefitting from a familiarity with the researcher and the protocol that would have been lacking at T1. This dynamic change may have influenced the results. Performance on the emotional Stroop can be hampered by emotional states like anxiety (i.e., task performance on the 'negative' condition can be slower due to the greater salience of negative words), which is the very reason the task is used in clinical assessment (Williams et al., 1996). Conversely though, a case could also reasonably be made that participants have greater levels of anxiety at the T2 session, for example arising from a concern to 'improve' their performance. Thus, while it is possible that factors like mood did affect test (and interview) performance, it is difficult to gauge the impact with accuracy. Future longitudinal research might incorporate a state specific measure of mood (e.g., Watson, Clark, and Tellegen's (1988) Positive And Negative Affect Scale) into the protocol to account for such factors.

The qualitative component of the study also raises certain issues. In qualitative research, a commitment to reflexivity means recognising that the methodological and epistemological choices of the research team influenced the data at all stages of the research process (Cutcliffe, 2005). For example, the data elicited from interviews is shaped through factors such as the mood of participants (as discussed above), the choice of interview questions and the expectations of the interviewer. Regarding question choice and interviewer expectations, it might be argued that the research question itself - i.e., whether mindfulness meditation facilitates decentring - led to the 
research team actively looking for a positive finding in the interviews. Although the constant comparison analytic method used allows themes to 'emerge' inductively from the data, the notion that the expectations of the research team influenced the subsequent analysis cannot be ruled out. However, the convergence of the quantitative and qualitative data means that we can have a degree of confidence that our interpretations were not simply imposed upon the data, but reflected actual patterns of cognitive development.

As such, it may be argued that mindfulness meditation is one way in which men can learn to decentre; consequently, by learning to do so, men may become more tolerant and show greater equanimity in the face of negative qualia, thus lessening their tendency to engage in maladaptive avoidance coping responses, and increasing their wellbeing more generally. These findings might have useful applications; for instance, young men might be encouraged to adopt meditation practices to equip them with valuable cognitive and emotional skills, helping to overcome deficits that this section of the population may be particularly liable to, thus enhancing the wellbeing of men themselves and of those around them. Future work could also be undertaken with female meditators to examine any sex/gender differences in the development of decentring skills, thereby furthering our understanding and appreciation of mindfulness more generally.

\section{Authors}

Tim Lomas

University of East London

t.lomas@uel.ac.uk

Trudi Edginton

University of Westminster

Tina Cartwright

University of Westminster

Damien Ridge

University of Westminster

\section{Publishing Timeline}

Received 13 January 2015

Accepted 19 July 2015

Published 3 August 2015

\section{References}

Addis, M. E. (2008). Gender and depression in men. Clinical Psychology: Science and Practice, 15(3), 153168. http://dx.doi.org/10.1111/j.1468-2850.2008.00125.x

Aldao, A., Nolen-Hoeksema, S., \& Schweizer, S. (2010). Emotion-regulation strategies across psychopathology: A meta-analytic review. Clinical Psychology Review, 30(2), 217-237. http://dx.doi.org/10.1016/j.cpr.2009.11.004

Anderson, C. (2010). Presenting and evaluating qualitative research. American Journal of Pharmaceutical Education, 74(8), 141. http://dx.doi.org/10.5688/aj7408141

Austin, J. H. (1998). Zen and the brain: Toward an understanding of meditation and consciousness. Cambridge, MA: MIT Press. 
Becker, E. S., Rinck, M., Margraf, J., \& Roth, W. T. (2001). The emotional Stroop effect in anxiety disorders: General emotionality or disorder specificity? Journal of Anxiety Disorders, 15(3), 147-159. http://dx.doi.org/10.1016/S0887-6185(01)00055-X

Benton, A. L. (1989). Multilingual aphasia examination. Iowa City, Iowa: AJA Associates.

Bishop, S. R., Lau, M., Shapiro, S., Carlson, L., Anderson, N. D., Carmody, J., . . Devins, G. (2004). Mindfulness: A proposed operational definition. Clinical Psychology: Science and Practice, 11(3), 230241. http://dx.doi.org/10.1093/clipsy.bph077

Block, N. (1995). On a confusion about a function of consciousness. Behavioral and Brain Sciences, 18(2), 227-287. http://dx.doi.org/10.1017/S0140525X00038188

Bluck, R. (2006). British Buddhism: Teachings, practice and development. London: Routledge.

Borton, J. L. S., Markowitz, L. J., \& Dieterich, J. (2005). Effects of suppressing negative self-referent thoughts on mood and self-esteem. Journal of Social and Clinical Psychology, 24(2), 172-190. http://dx.doi.org/10.1521/jscp.24.2.172.62269

Botvinick, M. M., Cohen, J. D., \& Carter, C. S. (2004). Conflict monitoring and anterior cingulate cortex: An update. Trends in Cognitive Sciences, 8(12), 539-546. http://dx.doi.org/10.1016/j.tics.2004.10.003

Brown, K. W., Ryan, R. M., \& Creswell, J. D. (2007). Mindfulness: Theoretical foundations and evidence for its salutary effects. Psychological Inquiry, 18(4), 211-237. http://dx.doi.org/10.1080/10478400701598298

Chambers, R., Gullone, E., \& Allen, N. B. (2009). Mindful emotion regulation: An integrative review. Clinical Psychology Review, 29(6), 560-572. http://dx.doi.org/10.1016/j.cpr.2009.06.005

Chambers, R., Lo, B., \& Allen, N. (2008). The impact of intensive mindfulness training on attentional control, cognitive style, and affect. Cognitive Therapy and Research, 32(3), 303-322. http://dx.doi.org/10.1007/s10608-007-9119-0

Chiesa, A., Calati, R., \& Serretti, A. (2011). Does mindfulness training improve cognitive abilities? A systematic review of neuropsychological findings. Clinical Psychology Review, 31(3), 449-464. http://dx.doi.org/10.1016/j.cpr.2010.11.003

Cutcliffe, J. R. (2005). Adapt or adopt: Developing and transgressing the methodological boundaries of grounded theory. Journal of Advanced Nursing, 51(4), 421-428. http://dx.doi.org/10.1111/j.13652648.2005.03514.x

Dalen, J., Smith, B. W., Shelley, B. M., Sloan, A. L., Leahigh, L., \& Begay, D. (2010). Pilot study: Mindful Eating and Living (MEAL): Weight, eating behavior, and psychological outcomes associated with a mindfulness-based intervention for people with obesity. Complementary Therapies in Medicine, 18(6), 260-264. http://dx.doi.org/10.1016/j.ctim.2010.09.008

Fresco, D. M., Moore, M. T., van Dulmen, M. H. M., Segal, Z. V., Ma, S. H., Teasdale, J. D., \& Williams, J. M. G. (2007). Initial psychometric properties of the experiences questionnaire: Validation of a selfreport measure of decentering. Behavior Therapy, 38(3), 234-246. http://dx.doi.org/10.1016/j.beth.2006.08.003

Garland, E. L., Gaylord, S. A., Boettiger, C. A., \& Howard, M. O. (2010). Mindfulness training modifies cognitive, affective, and physiological mechanisms implicated in alcohol dependence: Results of a randomized controlled pilot trial. Journal of Psychoactive Drugs, 42(2), 177-192. http://dx.doi.org/10.1080/02791072.2010.10400690

Goleman, D. (1988). The meditative mind: The varieties of meditative experience. New York: Tarcher.

Grossman, P., Niemann, L., Schmidt, S., \& Walach, H. (2004). Mindfulness-based stress reduction and health benefits: A meta-analysis. Journal of Psychosomatic Research, 57(1), 35-43. http://dx.doi.org/10.1016/S0022-3999(03)00573-7

Hart, R., Ivtzan, I., \& Hart, D. (2013). Mind the gap in mindfulness research: A comparative account of the leading schools of thought. Review of General Psychology, 17(4), 453-466.

http://dx.doi.org/10.1037/a0035212

Hausknecht, J. P., Halpert, J. A., Di Paolo, N. T., \& Moriarty Gerrard, M. O. (2007). Retesting in selection: A meta-analysis of coaching and practice effects for tests of cognitive ability. Journal of Applied Psychology, 92(2), 373-385. http://dx.doi.org/10.1037/0021-9010.92.2.373 
Hayes-Skelton, S. A., \& Graham, J. R. (2013). Decentering as a common link among mindfulness, cognitive reappraisal, and social anxiety. Behavioural and Cognitive Psychotherapy, 41(3), 317-328. http://dx.doi.org/10.1017/S1352465812000902

Heeren, A., Van Broeck, N., \& Philippot, P. (2009). The effects of mindfulness on executive processes and autobiographical memory specificity. Behaviour Research and Therapy, 47(5), 403-409. http://dx.doi.org/10.1016/j.brat.2009.01.017

Hodgins, H. S., \& Adair, K. C. (2010). Attentional processes and meditation. Consciousness and Cognition, 19(4), 872-878. http://dx.doi.org/10.1016/j.concog.2010.04.002

Jha, A. P., Krompinger, J., \& Baime, M. J. (2007). Mindfulness training modifies subsystems of attention. Cognitive, Affective, \& Behavioral Neuroscience, 7(2), 109-119. http://dx.doi.org/10.3758/CABN.7.2.109

Kabat-Zinn, J. (1982). An outpatient program in behavioral medicine for chronic pain patients based on the practice of mindfulness meditation: Theoretical considerations and preliminary results. General Hospital Psychiatry, 4(1), 33-47. http://dx.doi.org/10.1016/0163-8343(82)90026-3

Kabat-Zinn, J. (2003). Mindfulness-based interventions in context: Past, present, and future. Clinical Psychology: Science and Practice, 10(2), 144-156. http://dx.doi.org/10.1093/clipsy.bpg016

Koch, C., \& Tsuchiya, N. (2007). Attention and consciousness: Two distinct brain processes. Trends in Cognitive Sciences, 11(1), 16. http://dx.doi.org/10.1016/j.tics.2006.10.012

Kozasa, E. H., Radvany, J., Barreiros, M. A., Leite, J. R., \& Amaro, J. E. (2008). Preliminary functional magnetic resonance imaging Stroop task results before and after a zen meditation retreat. Psychiatry and Clinical Neurosciences, 62(3), 366. http://dx.doi.org/10.1111/j.1440-1819.2008.01809.x

Langer, E. J. (1989). Mindfulness. Cambridge, MA: Da Capo Press.

Levant, R. F. (1998). Desperately seeking language: Understanding, assessing, and treating normative male alexithymia. New York: John Wiley \& Sons Inc.

Lutz, A., Slagter, H. A., Dunne, J. D., \& Davidson, R. J. (2008). Attention regulation and monitoring in meditation. Trends in Cognitive Sciences, 12(4), 163-169. http://dx.doi.org/10.1016/j.tics.2008.01.005

Lykins, E., Baer, R., \& Gottlob, L. (2012). Performance-based tests of attention and memory in long-term mindfulness meditators and demographically matched nonmeditators. Cognitive Therapy and Research, 36(1), 103-114. http://dx.doi.org/10.1007/s10608-010-9318-y

MacLeod, C. M., \& Dunbar, K. (1988). Training and Stroop-like interference: Evidence for a continuum of automaticity. Journal of Experimental Psychology: Learning, Memory, and Cognition, 14(1), 126-135. http://dx.doi.org/10.1037/0278-7393.14.1.126

Marshall, M. (1996). Sampling for qualitative research. Family Practice, 13, 522-525. http://dx.doi.org/10.1093/fampra/13.6.522

Mason, J. (2006). Mixing methods in a qualitatively driven way. Qualitative Research, 6(1), 9-25. http://dx.doi.org/10.1177/1468794106058866

Mathews, A., \& MacLeod, C. (1994). Cognitive approaches to emotion and emotional disorders. Annual Review of Psychology, 4, 25-50. http://dx.doi.org/10.1146/annurev.ps.45.020194.000325

McManus, S., Meltzer, H., Brugha, T., Bebbington, P., \& Jenkins, R. (2009). Adult psychiatric morbidity in England, 2007: Results of a household survey. London, England: NHS Information Centre for Health and Social Care.

Mirsky, A., Anthony, B., Duncan, C., Ahearn, M., \& Kellam, S. (1991). Analysis of the elements of attention: A neuropsychological approach. Neuropsychology Review, 2(2), 109-145. http://dx.doi.org/10.1007/BF01109051

Moore, A., \& Malinowski, P. (2009). Meditation, mindfulness and cognitive flexibility. Consciousness and Cognition, 18(1), 176-186. http://dx.doi.org/10.1016/j.concog.2008.12.008

Nelson, H. R., \& Willison, J. R. (1991). National Adult Reading Test (NART): Test Manual (part II). Windsor, UK: NFER-Nelson.

Norman, W., \& Shallice, T. (1986). Attention to action. In R. J. Davidson, G. E. Schwartz \& D. Shapiro (Eds.), Consciousness and self regulation: Advances in research and theory, Vol. 4 (pp. 1-18). New York: Plenum.http://dx.doi.org/10.1007/978-1-4757-0629-1 1

Office for National Statistics (2012). Alcohol-related Deaths in the UK, 2010.

Office for National Statistics (2014). Suicides in the United Kingdom, 2012 Registrations. 
Pollack, W. S. (1998). Mourning, melancholia, and masculinity: Recognizing and treating depression in men. In W. S. Pollack \& R. F. Levant (Eds.), New psychotherapy for men (pp. 147-166). Hoboken, NJ: John Wiley and Sons.

Posner, M. I., \& Petersen, S. E. (1990). The attention system of the human brain. Annual Review of Neuroscience, 13(1), 25-42. http://dx.doi.org/10.1146/annurev.ne.13.030190.000325

Rafal, R. D., \& Posner, M. I. (1987). Deficits in human visual spatial attention following thalamic lesions. Proceedings of the National Academy of Sciences, 84(20), 7349-7353. http://dx.doi.org/10.1073/pnas.84.20.7349

Raffone, A., \& Srinivasan, N. (2010). The exploration of meditation in the neuroscience of attention and consciousness. Cognitive Processing, 11(1), 1-7. http://dx.doi.org/10.1007/s10339-009-0354-z

Riemann, B. C., \& McNally, R. J. (1995). Cognitive processing of personally relevant information. Cognition and Emotion, 9(4), 325. http://dx.doi.org/10.1080/02699939508408970

Schütze, R., Rees, C., Preece, M., \& Schütze, M. (2010). Low mindfulness predicts pain catastrophizing in a fear-avoidance model of chronic pain. Pain, 148(1), 120-127. http://dx.doi.org/10.1016/j.pain.2009.10.030

Shapiro, S. L., Astin, J. A., Bishop, S. R., \& Cordova, M. (2005). Mindfulness-based stress reduction for health care professionals: Results from a randomized trial. International Journal of Stress Management, 12(2), 164-176. http://dx.doi.org/10.1037/1072-5245.12.2.164

Shapiro, S. L., Carlson, L. E., Astin, J. A., \& Freedman, B. (2006). Mechanisms of mindfulness. Journal of Clinical Psychology, 62(3), 373-386. http://dx.doi.org/10.1002/jclp.20237

Shonin, E., Van Gordon, W., \& Griffiths, M. D. (2013). Mindfulness-based interventions: Towards mindful clinical integration. Frontiers in Psychology, 4(194). http://dx.doi.org/10.3389/fpsyg.2013.00194

Strauss, A., \& Corbin, J. (1998). Basics of qualitative research: Techniques and procedures for developing Grounded Theory (2nd ed.). Thousand Oaks, CA Sage.

Stroop, J. R. (1935). Studies of interference in serial verbal reactions. Journal of Experimental Psychology, 18(6), 643-662. http://dx.doi.org/10.1037/h0054651

Walsh, R., \& Shapiro, S. L. (2006). The meeting of meditative disciplines and western psychology: A mutually enriching dialogue. American Psychologist, 61(3), 227-239. http://dx.doi.org/10.1037/0003066X.61.3.227

Watson, D., Clark, L. A. C., \& Tellegen, A. (1988). Development and validation of brief measures of positive and negative affect: The PANAS scales. Journal of Personality and Social Psychology, 54, 10631070. http://dx.doi.org/10.1037/0022-3514.54.6.1063

Wenk-Sormaz, H. (2005). Meditation can reduce habitual responding. Alternative Therapies in Health and Medicine, 11(2), 42-58.

Williams, J. M. G., Mathews, A., \& MacLeod, C. (1996). The emotional Stroop task and psychopathology. Psychological Bulletin, 121(1), 3-24. http://dx.doi.org/10.1037/0033-2909.120.1.3

Zeidan, F., Johnson, S. K., Diamond, B. J., David, Z., \& Goolkasian, P. (2010). Mindfulness meditation improves cognition: Evidence of brief mental training. Consciousness and Cognition, 19(2), 597-605. http://dx.doi.org/10.1016/j.concog.2010.03.014

Zindel, V., Segal, J., Williams, M. G., \& Teasdale, J. D. (2002). Mindfulness-based cognitive therapy for depression: A new approach to preventing relapse. New York: Guilford. 